\title{
6- and 8-Prenylnaringenin, Novel Natural Histone Deacetylase Inhibitors Found in Hops, Exert Antitumor Activity on Melanoma Cells
}

\author{
Sascha Venturellia Heike Niessner ${ }^{\mathrm{b}} \quad$ Tobias Sinnberg $^{\mathrm{b}} \quad$ Alexander Berger $^{\mathrm{a}}$ \\ Markus Burkard ${ }^{\mathrm{a}}$ Corinna Urmann ${ }^{c} \quad$ Kathrin Donaubauer ${ }^{d} \quad$ Alexander Böcker $^{\mathrm{e}}$ \\ Christian Leischner ${ }^{\mathrm{a}} \quad$ Herbert Rieplc $^{\mathrm{c}} \quad$ Jan Frank $^{\dagger} \quad$ Ulrich M Lauerg,h $^{\mathrm{h}} \quad$ Claus Garbe $^{\mathrm{b}}$ \\ Christian Busch ${ }^{b}$
}

anstitute of Physiology, Department of Vegetative and Clinical Physiology, University of Tuebingen, Tuebingen, 'bivision of Dermato-Oncology, Department of Dermatology and Allergology, University of Tuebingen, Tuebingen, 'Hochschule Weihenstephan-Triesdorf, TUM Campus Straubing, Division of Organic and Analytic Chemistry, Straubing, dDepartment of Physiology, Technical University of Munich, Munich, eEvotec AG, Hamburg, fInstitute of Biological Chemistry and Nutrition, University of Hohenheim, Stuttgart, ' $D$ Department of Internal Medicine VIII, University Hospital Tuebingen, Tuebingen, hGerman Cancer Consortium (DKTK), DKFZ partner site Tuebingen, Tuebingen, Germany

\section{Key Words}

6-prenylnaringenin $\bullet$ 8-prenylnaringenin $\bullet 6-P N \cdot 8-P N \cdot H D A C \cdot$ Histone deacetalyse inhibition - Melanoma - Therapy • Hops

\begin{abstract}
Background/Aims: Prenylnaringenins are natural prenylflavonoids with anticancer properties. However, the underlying mechanisms have not been elucidated yet. Here we report a novel mode of action of 6- and 8-prenylnaringenin (PN) on human melanoma cells: Inhibition of cellular histone deacetylases (HDACs). Methods: We performed in silico and in vitro analyses using 6-PN or 8-PN to study a possible interaction of 6-PN or 8-PN with HDAC as well as Western blot and FACS analyses, real-time cell proliferation and cell viability assays to assess the impact of 6-PN and 8-PN on human metastatic melanoma cells. Results: In silico, 6-PN and 8-PN fit into the binding pocket of HDAC2, 4, 7 and 8, binding to the zinc ion of their catalytic center that is essential for enzymatic activity. In vitro, $100 \mu \mathrm{mol} / \mathrm{L}$ of $6-\mathrm{PN}$ or 8-PN inhibited all 11 conserved human HDAC of class I, II and IV. In clinical oncology HDAC inhibitors are currently investigated as new anticancer compounds. In line, treatment of SK-MEL-28 cells with 6-PN or 8-PN induced a hyperacetylation of histone complex $\mathrm{H} 3$ within 2 h. Further, 6-PN or 8-PN mediated a prominent, dose-dependent reduction of cellular proliferation and viability of SK-MEL-28 and BLM melanoma cells. This effect was apoptosis-independent and

\begin{tabular}{ll}
\hline PD Dr. med. Christian Busch & Division of Dermato-Oncology, Department of Dermatology and Allergology, University of \\
& Tuebingen, Liebermeisterstrasse 25, 72076 Tuebingen (Germany) \\
& E-Mail Christian.Busch@med.uni-tuebingen.de
\end{tabular}
\end{abstract}




\section{Cellular Physiology Cell Physiol Biochem 2018;51:543-556 \\ \begin{tabular}{ll|l} 
and Biochemistry Published onlIne: 20 November 2018 & $\begin{array}{l}\text { @ } 2018 \text { The Author(s). Published by S. Karger AG, Basel } \\
\text { www.karger.com/cpb }\end{array}$ \\
\hline
\end{tabular} \\ Venturelli et al.: 6-PN and 8-PN are Novel $\mathrm{HDACi}$}

accompanied by down-regulation of mTOR-specific pS6 protein via pERK/pP90 in SK-MEL-28 cells. Conclusion: The identification of a broad inhibitory capacity of 6-PN and 8-PN for HDAC enzymes with antiproliferative effects on melanoma cells opens the perspective for clinical application as novel anti-melanoma drugs and the usage as innovative lead structures for chemical modification to enhance pharmacology or inhibitory activities.

(C) 2018 The Author(s)

Published by S. Karger AG, Basel

\section{Introduction}

Increasing evidence indicates dietary chemo-prevention as a valuable strategy to either prevent cancer or impair its progression [1]. Among chemo-preventive agents, natural non-toxic products have been scrutinized for their potential to alter the development or progression of cancer [2,3]. Studies of several plant compounds, e.g. flavonoids, suggest that these molecules can harbor cancer chemo-preventive and/or therapeutic activities $[4,5]$.

Flavonoids are a large group of low molecular weight polyphenolic compounds found in plants and consist of flavones, flavonols, flavanones, flavan-3-ols, isoflavones as well as anthocyanins [6]. Flavonoids, among other things, play a role in the defense against microorganisms, pests [7] and oxidative stress [8]. 6-Prenylnaringenin (6-PN) and 8 -prenylnaringenin (8-PN) can be found in hops and beer in very low concentrations. The structure of this class of flavonoids is derived from 2-phenylchromen-4-one. 6-PN and 8-PN are isomers, the difference being the position where the prenyl 5 carbon membered chain ("prenyl"-group) is found. Both 6-PN and 8-PN are products of a ring closing reaction of a common ancestral molecule, desmethylxanthohumol, a polyphenol based on the structure of 1, 3-diphenyl-2-propen-1-one. 8-PN exhibits a strong binding affinity to rat uterus estrogen receptors and has been identified as a potent phytoestrogen [9] due to a characteristic distance of hydroxyl groups imitating $\beta$-estradiol. Flavonoids, including the prenylflavonoids, also show anticancer activities $[7,10]$. In particular, 8-PN inhibits angiogenesis induced by basic fibroblast growth factor and vascular endothelial growth factor in a three-dimensional collagen gel in vitro and in chorioallantoic membrane assays in vivo [11], mimics the effects of $17 \beta$-estradiol on MCF-7 breast cancer cells [12] and induces apoptosis in MCF-7 cells [13] and in a multi drug-resistant leukemia blast [14]. Inhibition of multi drug resistance-associated transporters P-glycoprotein and MRP1 by 8-PN was demonstrated [15]. Furthermore, 8-PN directly inhibits activation of PI(3)K/Akt pathway in MCF-7 cells in vitro [16]. 6-PN and 8-PN exhibit pronounced antiproliferative effects on PC-3 and DU145 human prostate cancer cell lines in vitro [17] in the absence of caspase-3 activation and typical apoptotic morphological features [18]. In the latter study formation of vacuoles was observed in PC-3 cells treated with 6-PN or in DU145 incubated with 6-PN and 8-PN, which was interpreted as induction of autophagy. A similar conclusion was drawn from the appearance of an intense intracytoplasmic vacuolization after treatment of estrogen-dependent T47-D breast cancer cells with 8-PN [19].

Despite the known potential of 6-PN and 8-PN as natural anticancer agents, the exact cellular mechanisms remain unknown. Today a variety of nutritional or dietary compounds are investigated for their potential to be epigenetically active, especially with regard to their antiproliferative properties [20]. Particularly epigenetic modulation of cellular histone proteins by histone deacetylases (HDAC) is of great interest due to the inherent antitumor activity of synthetic and natural HDAC inhibitors (HDACi). Several studies showed that HDACi mediate in vitro and in vivo changes in gene expression, cell cycle and/or apoptosis in a multitude of different tumor entities $[21,22]$. Therefore, the search for new HDACi compounds with potential for a clinical application in tumor therapy is important.

To date, it is unknown whether prenylflavonoids exert any HDACi activities and accordingly are able to epigenetically modulate gene expression of tumor cells by hyperacetylation. In the current study we therefore investigated the effect of 6-PN and 8-PN on human HDAC enzymes and their possible effects on cell proliferation and invasion in the human metastatic melanoma cell lines SK-MEL-28 and BLM. SK-Mel-28 and BLM cells were 


\section{Cellular Physiology Cell Physiol Biochem 2018;51:543-556 \begin{tabular}{l|l|l} 
and Biochemistry Published online: 20 November 2018 & $\begin{array}{l}\text { ( 2018 The Author(s). Published by S. Karger AG, Basel } \\
\text { www.karger.com/cpb }\end{array}$ \\
\hline
\end{tabular} \\ Venturelli et al.: 6-PN and 8-PN are Novel HDACi}

chosen as in vitro melanoma models due to their distinct mutation status. SK-Mel-28 cells have a mutant B-Raf (V600E) and wiltype N-Ras. Activating BRAF mutations are present in approximately $50 \%$ of all human primary melanomas. BLM cells are $\mathrm{N}$-Ras mutant and B-Raf wildtype. NRAS mutations can be found in $20-30 \%$ of human melanomas.

\section{Materials and Methods}

\section{In silico docking analysis}

In silico docking analyses for human HDAC2, 4, 7 and 8 with 6-PN, 8-PN and the two reference HDACi suberoylanilide hydroxamic acid (SAHA) and trichostatin A (TSA) were performed. All ligands were prepared using the molecular operation environment (MOE, version 2009.10, Chemical Computing Group Inc, Montreal, Canada). 3D representations of the ligands were obtained by energy minimization (Rebuild3D function with preservation of existing chiral centers) using MM94x force field and a Born Solvation model without cutoff constraints. All other parameters were left at default.

Crystal structures of HDAC2 (PDB code: 3max), HDAC4 (PDB code: 2vqm), HDAC7 (PDB code: 3c10) and HDAC8 (PDB code: 1t64) were retrieved from the protein data bank (PDB, http://www.ebi.ac.uk/pdbe/) and loaded into MOE. The Protonate3D functionality was applied to assign the correct ionization state and geometries to the protein atoms and to add hydrogen atoms. For the final docking water molecules were discarded. Docking was performed using GOLD (version 4.1.2, The Cambridge Crystallographic Data Center, Cambridge, UK). No additional protein preparation was applied. Binding sites were defined by all residues within $5 \AA$ distance from the corresponding ligands in the crystal structure. Docking was performed using GoldScore as scoring function. All other parameters were left at default. Docking poses were analyzed in MOE. Docking was validated by comparing the highest scoring docking pose of TSA to the pose of the ligand in the corresponding crystal structure of HDAC7 and HDAC8. In both cases excellent overlays were obtained with RMSDs below 1.5 A. Docking poses of 6-PN and 8-PN in the individual HDAC binding pockets were analyzed in MOE. To optimize the ligand-receptor interactions energy minimizations were applied using MM94x force field and a Born Solvation model without cutoff constraints.

\section{HDAC Inhibitor screening Assay}

Determination of HDACi activity was performed with HDAC assay kit (Active Motif, La Hulpe, Belgium) as described by the manufacturer with an incubation time of $2 \mathrm{~h}$ at $37^{\circ} \mathrm{C}$, using 6-PN and 8-PN at rising concentrations $(5,10,20,50$ and $100 \mu \mathrm{mol} / \mathrm{L}$, both from Sigma-Aldrich).

\section{HDAC inhibition profiling}

The human HDAC profiling assay was performed on basis of the Fluor de Lys ${ }^{\mathrm{TM}}$ technology by Scottish Biomedical, Glasgow, UK. The percentage inhibition values of $100 \mu \mathrm{mol} / \mathrm{L} 6-\mathrm{PN}$ and 8-PN (both from SigmaAldrich) against human HDAC enzymes HDAC1, HDAC2, HDAC3, HDAC4, HDAC5, HDAC6, HDAC7, HDAC8, HDAC9, HDAC10 and HDAC11 were determined. All assays were performed in 1\% DMSO (final).

\section{Cell Culture}

Metastatic melanoma cell lines SK-MEL-28 and BLM (kindly gifted by Meenhard Herlyn, Wistar Institute, Philadelphia, USA) were cultured in RPMI 1640 medium supplemented with $10 \%$ fetal bovine serum (FBS), $1 \%$ penicillin, and $1 \%$ streptomycin. All cell cultures were maintained at $37^{\circ} \mathrm{C}$ in a $95 \%$ air / $5 \% \mathrm{CO}_{2}$ atmosphere at $100 \%$ humidity. All cell culture experiments described in this study were performed with 6-PN and 8-PN purchased from Sigma-Aldrich; preliminary experiments (data not shown) were performed using synthesized 6-PN and 8-PN.

\section{Proliferation assay}

Melanoma cells were seeded in triplicate in 96-well plates at a density of 2, 500 cells per well in $50 \mu \mathrm{l}$ medium $\left(5 \times 10^{4}\right.$ cells per $\left.\mathrm{ml}\right)$. After $24 \mathrm{~h}$, medium was replaced by medium containing 6-PN, 8-PN (dissolved in DMSO), valproic acid (VPA, dissolved in $0,9 \% \mathrm{NaCl}$ solution) or SAHA (dissolved in DMSO) at the concentrations to be tested. Cells treated with culture medium without or with DMSO served as controls. Assay was started following incubation for $24 \mathrm{~h}$ or $96 \mathrm{~h}$. Medium was discarded, each well was washed two 


\section{Cellular Physiology Cell Physiol Biochem 2018;51:543-556 \begin{tabular}{ll|l} 
and Biochemistry Published online: 20 November 2018 & $\begin{array}{l}\text { (c) } 2018 \text { The Author(s). Published by S. Karger AG, Basel } \\
\text { www.karger.com/cpb }\end{array}$ \\
\hline
\end{tabular} \\ Venturelli et al.: 6-PN and 8-PN are Novel HDACi}

times with PBS (without $\mathrm{Ca}^{2+}$ and $\mathrm{Mg}^{2+}$ ) and $100 \mu \mathrm{l}$ of a solution containing $100 \mu \mathrm{g}$ 4-methylumbelliferyl heptanoate per ml PBS was added. Plates were incubated at $37^{\circ} \mathrm{C}$ for $1 \mathrm{~h}$ and measured in a Fluoroskan II (Labsystems, Helsinki, Finland), with a $\lambda$ em of $355 \mathrm{~nm}$ and a $\lambda$ ex of $460 \mathrm{~nm}$. The intensity of fluorescence indicates the number of viable cells in the wells [23].

\section{Real-Time Cell Monitoring Assay}

SK-MEL-28 and BLM cells $\left(2.5 \times 10^{3}\right.$ cells/well) were seeded in 96-well plates (E-Plate 96, Roche Applied Science, Mannheim, Germany). Cells were treated after $24 \mathrm{~h}$ with different concentrations of 6-PN or 8-PN (20, 50 and $100 \mu \mathrm{mol} / \mathrm{L})$ and monitored by measurements of electrical impedance in 15 min intervals for an overall time span of $104 \mathrm{~h}$ using the xCELLigence ${ }^{\circledR}$ SP system (Roche Applied Science). Cell index values were calculated using the RTCA Software (1.0.0.0805). All curves were normalized at the beginning of the treatment period $[24,25]$.

\section{FACS analyses}

SK-MEL-28 cells were treated with $100 \mu \mathrm{mol} / \mathrm{L}$ 6-PN or 8-PN. After $48 \mathrm{~h}$, cells $\left(1 \times 10^{6}\right)$ were harvested, washed with cold PBS, fixed with $75 \%$ ethanol and incubated at $4{ }^{\circ} \mathrm{C}$ for at least $1 \mathrm{~h}$. Cells were then centrifuged and washed twice in cold PBS. Intracellular DNA was labelled with propidium iodide solution (Sigma-Aldrich, Steinheim, Germany) (propidium iodide $50 \mu \mathrm{g} / \mathrm{ml}$ and RNase $100 \mu \mathrm{g} / \mathrm{ml}$ in PBS) and incubated at $4^{\circ} \mathrm{C}$ for $30 \mathrm{~min}$ in the dark. Cell cycle was analyzed using flow cytometry and FACSDiva software (BD Biosciences, Heidelberg, Germany). Results were expressed as mean \pm SD values of three independent experiments; each histogram represents at least 10, 000 individual events (measured cells). FACS analyses of SK-MEL-28 cells after treatment with 6-PN and 8-PN (100 $\mu \mathrm{mol} / \mathrm{L}, 4 \mathrm{~h}$ and $24 \mathrm{~h})$ for annexin V / PI staining was performed as described previously [26].

\section{Apoptosis assay}

Apoptosis induction was tested with the human Proteome Profiler apoptosis antibody array kit (R\&D Systems, Wiesbaden, Germany) as described by the manufacturer after treatment of SK-MEL-28 melanoma cells with $100 \mu \mathrm{mol} / \mathrm{L} 6$-PN or 8-PN for $4 \mathrm{~h}$.

\section{Immunoblotting}

SK-MEL-28 cells $\left(2 \times 10^{5}\right.$ cells/well) were seeded into 6 -well plates and treated the following day once as indicated. After incubation times of 1, 2, 4, 12 and $24 \mathrm{~h}$ the cells were harvested, washed once with PBS and resuspended in $100 \mu$ lysing-buffer (1\% Nonident P40, $500 \mathrm{mmol} / \mathrm{L}$ Tris-Base (pH 7.6), $150 \mathrm{mmol} / \mathrm{L}$ $\mathrm{NaCl})$. Lysates were stored at $-80^{\circ} \mathrm{C}$, thawed and refrozen 3 times and treated with sonifier $(60 \%$ output volume, $20 \mathrm{~s}$ ). Lysates $(50 \mu \mathrm{l})$ were separated on $12 \%$ SDS-polyacrylamide gels under reducing conditions and transferred to polyvinylidenedifluoride membranes (Hybond-P, Amersham Biosciences, Piscataway, NJ). Membranes were blocked in Tris-buffered saline (150 mmol/L NaCl, 13 mmol/L Tris, pH 7.5) containing $5 \%$ nonfat dry milk powder for $1 \mathrm{~h}$. Next, the membranes were incubated with anti-vinculin or anti-actin (1:5, 000, Sigma-Aldrich), anti-caspase-3 (1:1, 000), anti-AKT, anti-pAKT, anti-ERK, anti-pERK, anti-P90, anti-pP90, anti-P70S6 kinase and anti-pS6 protein (1:1, 000, all from Cell Signaling, Frankfurt, Germany) overnight at $4{ }^{\circ} \mathrm{C}$, then washed three times with TBS-T (TBS containing $0.02 \%$ Triton X-100) and incubated with peroxidase-conjugated anti-rabbit $(1: 8,000)$ or anti-mouse $(1: 4,000$, both from Bio Rad, Hercules, USA) for $45 \mathrm{~min}$. Membranes were washed six times in TBS-T and further detection was performed by the ECL Western blotting detection system on Hyperfilm-ECL (Amersham Biosciences, USA). For the detection with anti-acetyl-histone H3 (1:5, 000, Millipore, Billerica, USA) SK-MEL-28 cells $\left(2 \times 10^{5}\right.$ cells/well) were incubated for 1, 2, 4 and $12 \mathrm{~h}$ with 6-PN, 8-PN or DMSO.

\section{Statistical Analysis}

Statistical analyses for different assays were performed with One-way ANOVA Dunnett's multiple comparison test using GraphPad Prism version 4.00 (GraphPad Software, San Diego, CA, USA). According to this analysis a value of $* P<0.01$ was defined as statistically significant. 


\section{Cellular Physiology Cell Physiol Biochem 2018;51:543-556

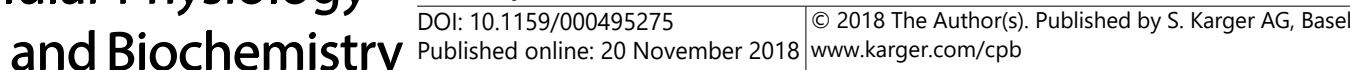

\section{Results}

In silico docking analyses predicted binding of 6-PN and 8-PN into human HDAC enzymes

To identify a potential HDACi activity of 6-PN and 8-PN (Fig. 1), first in silico docking analyses were performed with human HDAC class I members HDAC2 and HDAC8 as well as the class II members HDAC4 and HDAC7 (Fig. 2A). Important features of HDACi are the structural property to fit into the binding pocket of HDAC enzymes and the capacity to interact with key residues like the zinc ion in the catalytic center. According to the predicted interactions of the docking analysis 6-PN and 8-PN theoretically fulfill both requirements concerning HDAC2, HDAC4, HDAC7 and HDAC8, respectively (Fig. 2A). However, it was observed that no consistent binding mode was obtained for 6-PN and 8-PN across the different HDAC enzymes (i.e. different parts of 6-PN and 8-PN interact with the zinc ion). This renders the docking analysis of 6-PN and 8-PN difficult to interpret. The established HDACi trichostatin A (TSA; not clinically approved due to severe toxic side effects) and suberoylanilide hydroxamic acid (SAHA; clinically approved for cancer therapy) were also analyzed as reference inhibitors. For comparison of the docking results, the scoring function GoldScore was used. Interestingly, 6-PN and 8-PN yielded higher GoldScores than previously published scores for TSA or SAHA [27] for HDAC4 (6-PN: 66.5; 8-PN: 57.6), HDAC7 (6-PN: 56.9; 8-PN: 56.7) and HDAC8 (6-PN: 59.5; 8-PN: 64.8), and GoldScores comparable to (6-PN) or lower (8-PN) than TSA or SAHA for HDAC2 (6-PN: 62.8; 8-PN: 37), with the restriction mentioned above. Taken together, based on the in silico data both 6-PN and 8-PN were suggested to exhibit inhibitory activity against HDAC enzymes of class I and II comparable to standard HDACi such as TSA and SAHA.

In vitro screening confirmed a pronounced pan-HDACi activity of 6-PN and 8-PN

To further substantiate the predicted HDACi activity in vitro, 6-PN and 8-PN were screened in a HDACi assay. Employing standardized nuclear extract of HeLa cells as a human HDAC enzyme source, 6-PN and 8-PN showed a dose-dependent HDAC inhibitory activity (Fig. 2B). Low concentrations of 6-PN $(5 \mu \mathrm{mol} / \mathrm{L})$ and 8-PN $(10 \mu \mathrm{mol} / \mathrm{L})$ already showed inhibitory effects and $100 \mu \mathrm{mol} / \mathrm{L}$ resulted in an inhibition rate $\geq 50 \%$ (Fig. 2B). $100 \mu \mathrm{mol} / \mathrm{L}$ SAHA was used as control HDACi. In conclusion, 6-PN and 8-PN displayed a substantial HDACi activity on human HDAC enzymes in vitro.

To confirm the in silico and in vitro results and to apportion the inhibitor activity of 6-PN and 8-PN, a profiling analysis with all known human HDAC enzymes of class I, II and IV was performed (Fig. 2C). On basis of the HDACi screening assay and the resulted inhibition values, $100 \mu \mathrm{mol} / \mathrm{L} 6$-PN or 8-PN and TSA (as reference HDACi; in the optimized concentrations

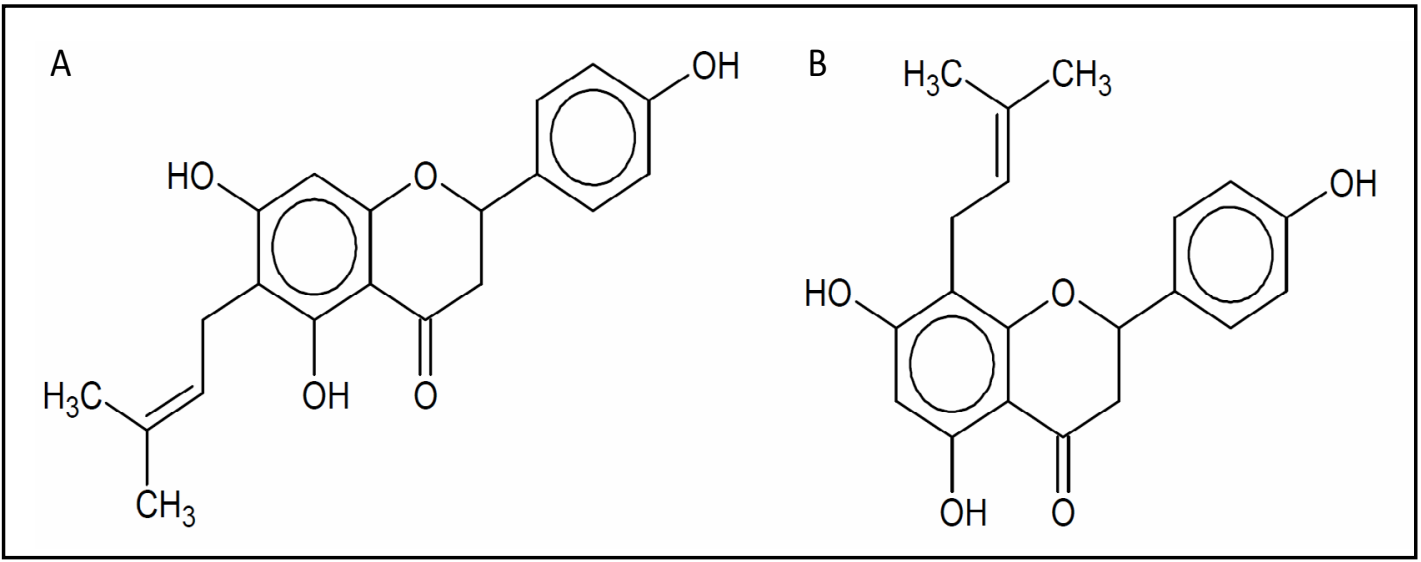

Fig. 1. Chemical structures of 6-PN and 8-PN. Depicted are the chemical structures of 6-prenylnaringenin (5,7-dihydroxy-2-(4-hydroxy-phenyl)-6-(3-methyl-but-2-enyl)-chroman-4-one) (A) and 8-prenylnaringenin (5,7-dihydroxy-2-(4-hydroxy-phenyl)-8-(3-methyl-but-2-enyl)-chroman-4-one) (B). 


\section{Cellular Physiology Cell Physiol Biochem 2018;51:543-556

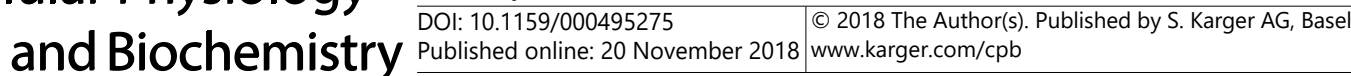 Venturelli et al.: 6-PN and 8-PN are Novel HDACi}

of $0.01,1$ and $10 \mu \mathrm{mol} / \mathrm{L}$ ) were chosen to test all conserved eleven HDAC enzymes and to ensure adequate inhibitor concentration. In line with the docking results and the screening assay, 6-PN as well as 8-PN strongly inhibited HDAC activity of all tested human HDAC (Fig. 2C). According to the HDAC inhibition values for HDAC1-11, both prenylflavonoids can be considered as pan-HDACi at high concentrations.

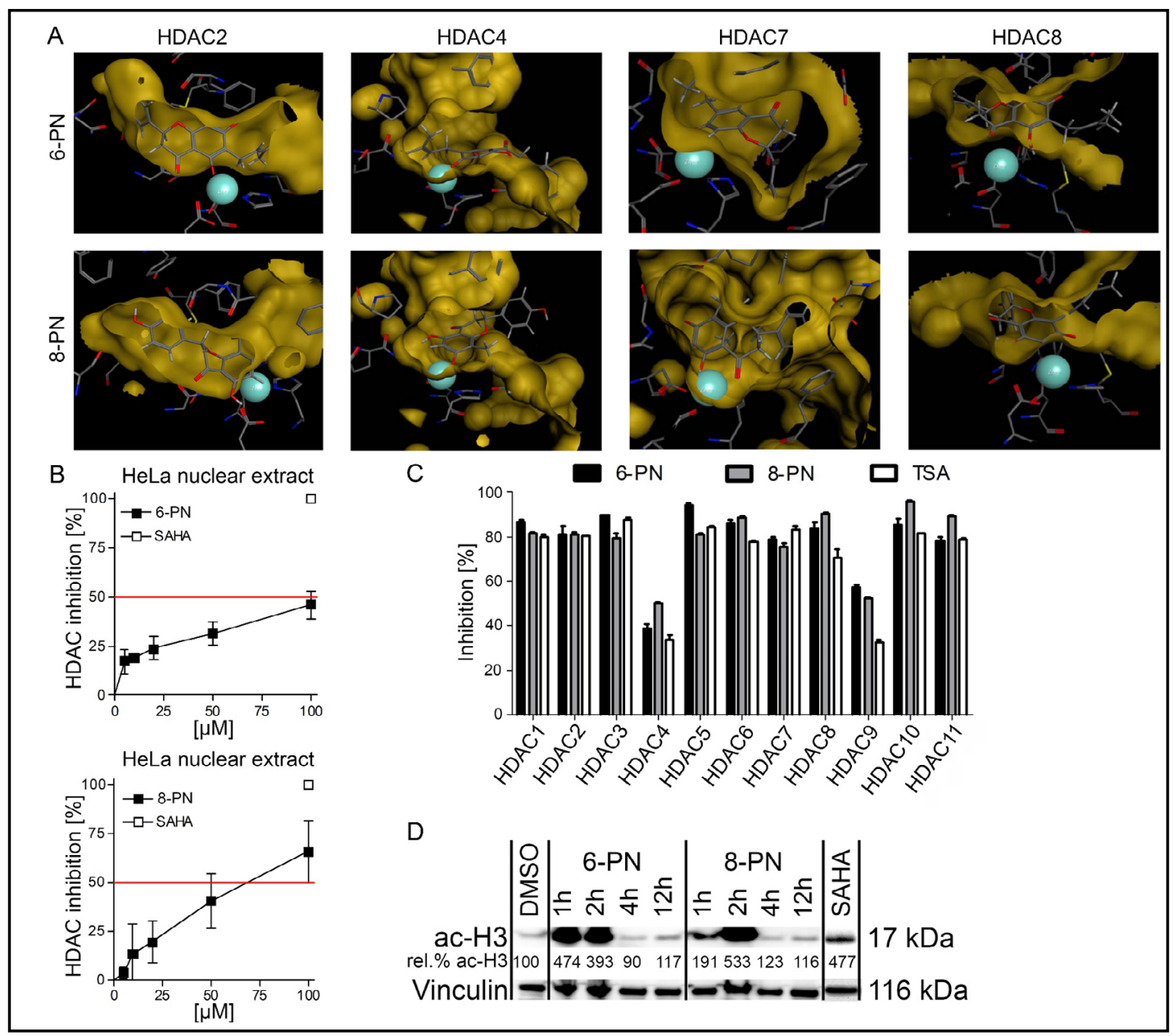

Fig. 2. 6-PN and 8-PN are inhibitors of human-derived histone deacytelases and induce hyperacetylation in SK-MEL-28 melanoma cells. Result of the in silico docking analysis of 6-PN and 8-PN with crystal structures of HDAC2, HDAC4, HDAC7 and HDAC8. The analysis shows the predicted binding mode of 6-PN and 8-PN in the HDAC binding pockets. Both molecules are predicted to interact with the zinc ion (turquoise sphere) as well as other residues of the catalytic centre (A). Overall HDAC inhibition in cellular extracts of the human cell line HeLa by increasing concentrations of 6-PN and 8-PN (5, 10, 20, 50 and $100 \mu \mathrm{mol} / \mathrm{L}$ ). As reference inhibitor $100 \mu \mathrm{mol} / \mathrm{L}$ SAHA was used. All concentrations were tested three times in triplicate. Data are means \pm SD (B). Specific fluorometric profiling assay using recombinant human HDAC of classes I, II and IV. Specific inhibition values were generated for the treatment with $100 \mu \mathrm{mol} / \mathrm{L}$ 6-PN and 8-PN.

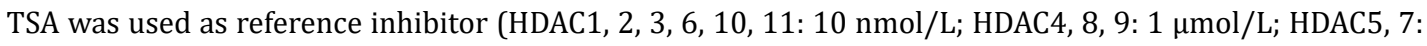
$10 \mu \mathrm{mol} / \mathrm{L}$ ). Inhibition values for every HDAC were yielded by one experiment performed in duplicates. Shown are means \pm SD (C). Western blot analysis of acetylated histone complex H3 in cellular lysates of SK-MEL-28 cells treated with $100 \mu \mathrm{mol} / \mathrm{L}$ 6-PN or 8-PN for 1, 2, 4, or $12 \mathrm{~h}$, or with $100 \mu \mathrm{mol} / \mathrm{L}$ SAHA (as reference HDACi) for $24 \mathrm{~h}$. Equal protein loading was verified by vinculin staining (lower rows). At $2 \mathrm{~h}$ after PN exposure a prominent up-regulation of ac-H3 is detectable. Protein expression levels were estimated performing a densitometric analysis (D).

\section{KARGER}


Cellular Physiology

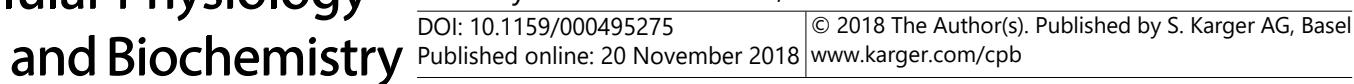
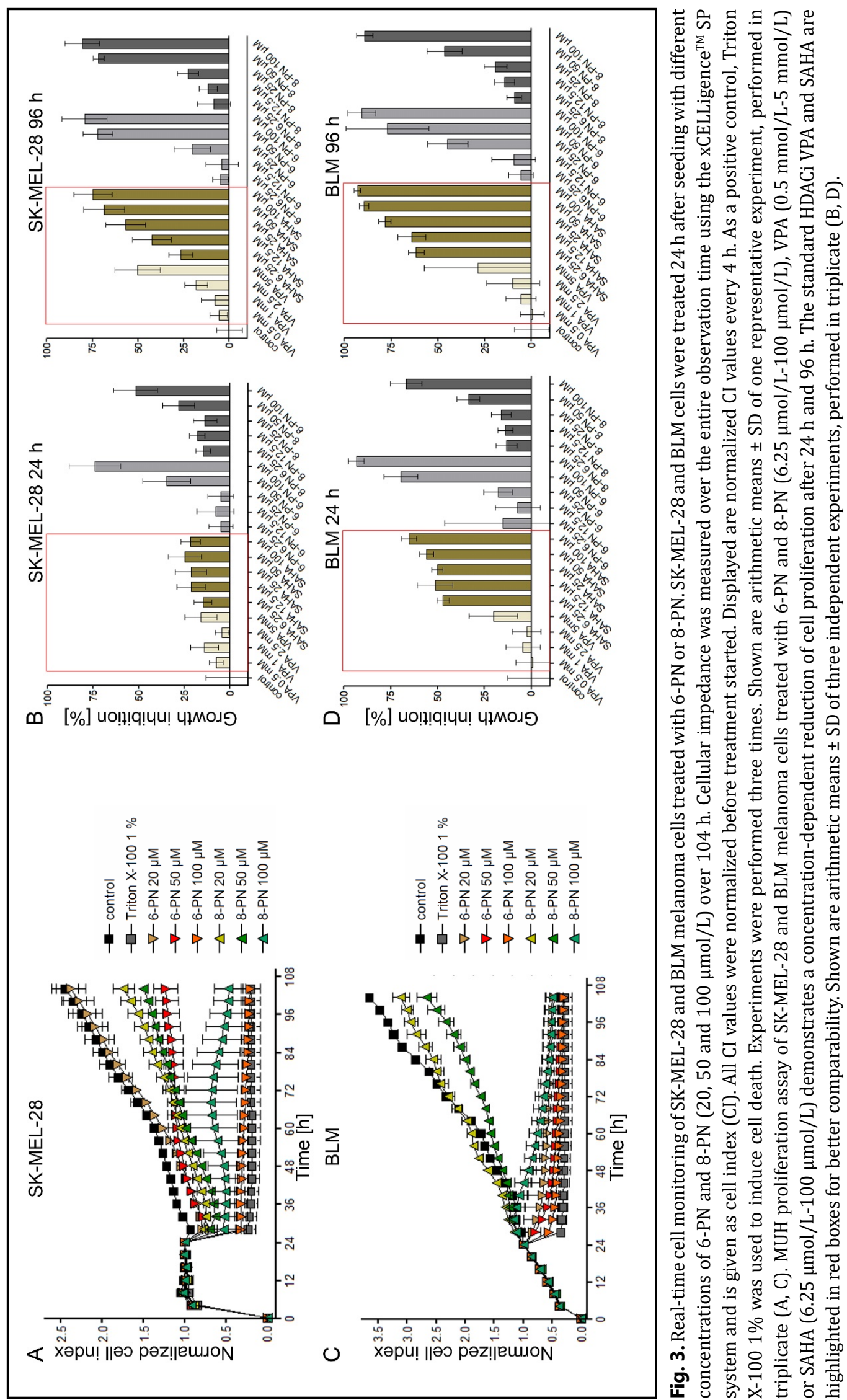


\section{Cellular Physiology Cell Physiol Biochem 2018;51:543-556 \begin{tabular}{ll|l} 
and Biochemistry & $\begin{array}{l}\text { DOl: 10.1159/000495275 } \\
\text { Published online: } 20 \text { November } 2018\end{array}$ & $\begin{array}{l}\text { (2018 The Author(s). Published by S. Karger AG, Basel } \\
\text { www.karger.com/cpb }\end{array}$ \\
\cline { 2 - 3 }
\end{tabular} \\ Venturelli et al.: 6-PN and 8-PN are Novel HDACi}

Hyperacetylation of histone H3 after 6-PN and 8-PN treatment in SK-MEL-28 melanoma cells

Incubation of cells with HDACi induces generally a hyperacetylation of histone proteins. Therefore, the acetylation status of the histone protein $\mathrm{H} 3$ after treatment with 6-PN or 8-PN was investigated. Corresponding to the HDACi screening results, a direct effect was monitored. Western blot analyses revealed a massive increase of histone complex $\mathrm{H} 3$ acetylation in SK-MEL-28 cells already $2 \mathrm{~h}$ after treatment with $100 \mu \mathrm{mol} / \mathrm{L} 6-\mathrm{PN}$ or 8-PN (quantified by densitometric analysis), when compared to DMSO-treated control cells (Fig. 2D). SAHA was used as control HDACi (at $100 \mu \mathrm{mol} / \mathrm{L}, 24 \mathrm{~h}$ treatment).

\section{6-PN and 8-PN decrease proliferation and viability in metastatic melanoma cells}

Due to the newly established HDACi activity of 6-PN and 8-PN and the observed hyperacetylation of histone protein $\mathrm{H} 3$ in human melanoma cells, the antiproliferative effects of the prenylnaringenins were tested. SK-MEL-28 and BLM cells were treated once with increasing concentrations of 6-PN or 8-PN (20,50 and $100 \mu \mathrm{mol} / \mathrm{L})$ and monitored continuously for an overall time of $104 \mathrm{~h}$ using a real-time cell monitoring assay (Fig. 3A, $\mathrm{C})$. The cell's impedance, depicted as cell index (CI), was measured reflecting changes of the cellular status. An increase in the CI generally displays cellular growth, whereas a decrease indicates perturbations of cell growth or viability. The normalized CI of SK-MEL-28 and BLM cells treated with 6-PN or 8-PN descended over time in comparison to the control at every concentration tested. Especially, incubation with 50 and $100 \mu \mathrm{mol} / \mathrm{L}$ of 6-PN as well as 8-PN showed a pronounced and rapid change of the measured CI. In line with the early HDACimediated hyperacetylation of histone H3 at $100 \mu \mathrm{mol} / \mathrm{L}$ for both PN in SK-MEL-28 cells, a rapid decline of the normalized CI was observed in both SK-MEL-28 and BLM cells already 4 $\mathrm{h}$ after beginning of treatment in comparison to the cells.

In order to substantiate the antiproliferative effects of 6-PN and 8-PN on SK-MEL-28 and BLM cells, additional proliferation assays were performed (Fig. 3B, D). According to the real-time cell monitoring assay already $20 \mu \mathrm{mol} / \mathrm{L}$ of $6-\mathrm{PN}$ or $8-\mathrm{PN}$ induced a distinct decline after $24 \mathrm{~h}$, which increased over time (compare Fig. 3A, C). Therefore, low concentrations were included in this assay and the cells were exposed to the prenylnaringenins for $24 \mathrm{~h}$ or for $96 \mathrm{~h}$. In concordance with previous results, concentrations of 50 and $100 \mu \mathrm{mol} / \mathrm{L}$ of 6-PN and 8-PN showed pronounced antiproliferative effects. 6-PN and 8-PN reduced cell proliferation up to $75 \%$ in SK-MEL-28 and $90 \%$ in BLM cells (Fig. 3B, D). When compared to the reference HDACi valproic acid (VPA) and SAHA (highlighted in red boxes for better visibility), the antiproliferative effects of the prenylnaringenins were more pronounced for 6-PN after $24 \mathrm{~h}$ of exposure to the substances. Together, this corroborates and extends our previously reported observation of potent antiproliferative effects of the prenylnaringenins against human prostate (PC-3) and renal cancer (U0.31) cells [10].

The induction of cell death in SK-MEL-28 cells by 6-PN and 8-PN is apoptosis-independent

To further narrow down the type of cell death induced by 6-PN and 8-PN, an apoptosis assay (Proteome Profiler apoptosis antibody array) was performed on SK-MEL-28 melanoma cells $4 \mathrm{~h}$ after exposure to $100 \mu \mathrm{mol} / \mathrm{L}$ 6-PN or 8-PN (Fig. 4A). Protein expression was estimated by densitometric analysis and confirmed that the decrease in proliferation of SKMEL-28 cells induced by 6-PN or 8-PN was not apoptosis-related. To verify this unexpected observation, we additionally performed Western blot analyses of SK-MEL-28 cells 1, 2, 4, 12 and $24 \mathrm{~h}$ after exposure to $100 \mu \mathrm{mol} / \mathrm{L} 6-\mathrm{PN}$ or 8-PN. For both prenylnaringenins decreased protein levels expression of caspase-3 (pro-apoptotic) and Bcl-xl (anti-apoptotic) were detected (not shown). However, we did not detect an additional band for cleaved caspase-3 for 6-PN, 8-PN or any of the applied reference HDACi (TSA, SAHA) or the vehicle control (DMSO) in SK-MEL-28 cells (Fig. 4B), thus corroborating the results from the apoptosisscreening assay described above (Fig. 4A). 


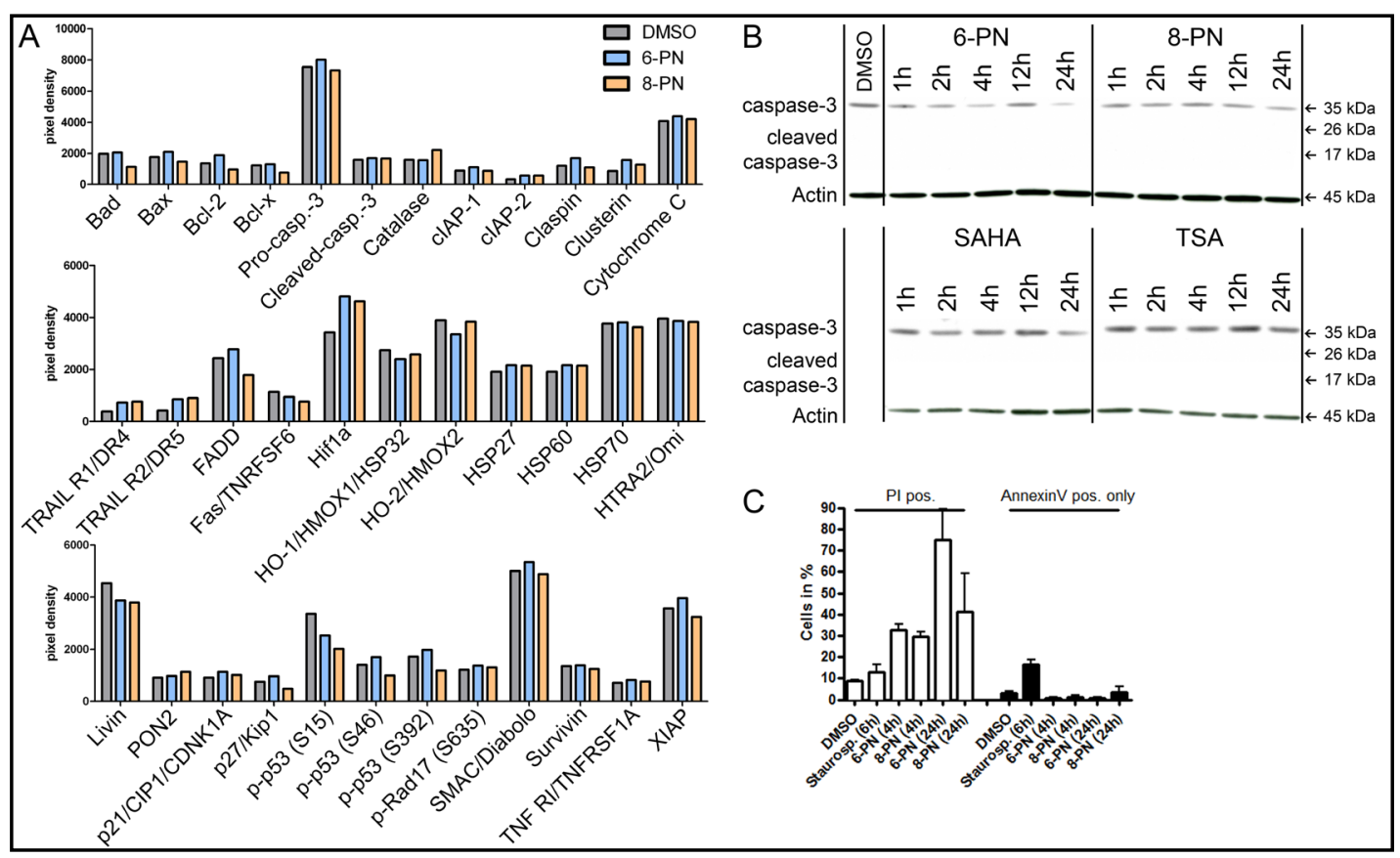

Fig. 4. Cell death induced by 6-PN and 8-PN is apoptosis-independent in SK-MEL-28 cells. Apoptosis assay (35 proteins) performed on lysates of SK-MEL-28 cells $4 \mathrm{~h}$ after exposure to $100 \mu \mathrm{mol} / \mathrm{L}$ 6-PN or 8-PN. Protein expression was quantified by densitometric analysis. Neither 6-PN nor 8-PN yielded a significant change of expression of the analyzed proteins involved in apoptosis (A). Western blot analysis of SKMEL-28 melanoma cells treated with $100 \mu \mathrm{mol} / \mathrm{L}$ of 6-PN, 8-PN, SAHA or TSA. DMSO was applied as control. Although a band for caspase-3 (35 kDa) is clearly visible for all treatments, no additional band for cleavedcaspase-3 (expected size: $17 \mathrm{kDa}$ ) was found upon any of the treatments (B). FACS analyses of SK-MEL-28 cells treated with $100 \mu \mathrm{mol} / \mathrm{L}$ 6-PN or 8-PN and stained for annexin V / PI; staurosporine was used as control for apoptosis induction and DMSO as vehicle control. PN-treatment did not increase the number of annexin V positive (apoptotic) cells (C).

This was verified by FACS cell-cycle analyses to screen for a possible increase of the sub-G1 fraction of cells (apoptotic cells) or for induction of a G2-arrest (inhibition of proliferation). Indeed, the FACS analysis showed an induction of G2-arrest in SK-MEL-28 cells $48 \mathrm{~h}$ after exposure to $100 \mu \mathrm{mol} / \mathrm{L}$ of 8 -PN when compared to the DMSO-treated control cells $(49.8 \%$ vs. $20.1 \%$ of cells in the G2 phase, respectively, (data not shown); the sub-G1 fraction (marking apoptotic cells) remained unaffected by 8-PN (data not shown). To further differentiate between induction of apoptosis and / or necrosis, we performed annexin $\mathrm{V}$ / PI staining of SK-MEL-28 cells $4 \mathrm{~h}$ and $24 \mathrm{~h}$ after exposure to 6-PN or 8-PN; $10 \mu \mathrm{mol} / \mathrm{L}$ staurosporine ( $6 \mathrm{~h}$ exposure) was used as positive control for induction of apoptosis; DMSO was used as vehicle control. Cells were then analyzed by FACS. In line with the results above, neither 6-PN nor 8-PN increased the number of annexin V positive (apoptotic) cells at $4 \mathrm{~h}$ or $24 \mathrm{~h}$ after treatment; as expected, staurosporine increased the number of annexin $\mathrm{V}$ positive cells (DMSO control: 2.5\%; staurosporine: $13.9 \%$; 6-PN $4 \mathrm{~h}$ and $24 \mathrm{~h}$ : $0.5 \%$ and $0.6 \%$; 8-PN $4 \mathrm{~h}$ and $24 \mathrm{~h}: 0.2 \%$ and $0.5 \%$; Fig. $4 \mathrm{C}$ ). In contrast, the number of PI positive (necrotic) cells strongly increased only after treatment with the prenylnaringenins (DMSO control: 7.9\%; staurosporine: 9.3\%; 6-PN $4 \mathrm{~h}$ and $24 \mathrm{~h}: 31.1 \%$ and 75.3\%; 8-PN $4 \mathrm{~h}$ and $24 \mathrm{~h}: 29.9 \%$ and 40.2\%, Fig. 4C). 


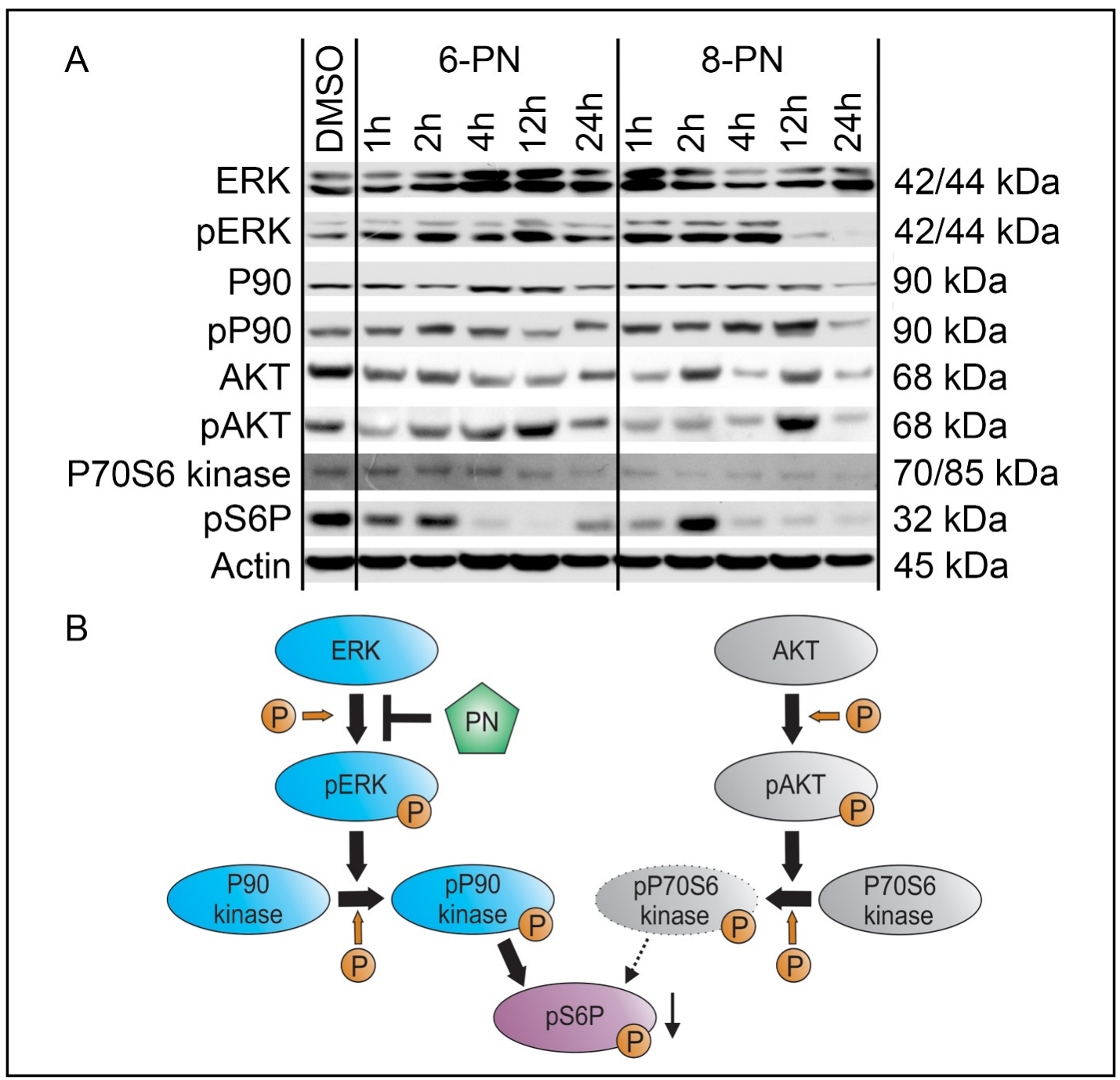

Fig. 5. 6-PN and 8-PN decrease potein expression of pS6P via down-regulation of pERK/pP90 in SK-MEL-28 cells. Western blot analyses of SK-MEL-28 melanoma cells 1, 2, 4, 12 and $24 \mathrm{~h}$ after incubation with 100 $\mu \mathrm{mol} / \mathrm{L} 6$ 6-PN or 8-PN. 6-PN and 8-PN induced a down-regulation of pS6P downstream of a decrease of pERK and pP90, respectively. In addition, 6-PN and 8-PN induced a time-dependent decrease of P70S6 kinase (A). Schematic drawing illustrating the Western blot results (B).

6-PN and 8-PN decrease expression of $p S 6 P$ via down-regulation of $p E R K / p P 90$ in $S K$ MEL-28 cells

Upon treatment of SK-MEL-28 cells with 6-PN or 8-PN, we detected an inconsistent expression of oncogenic AKT and phospho-AKT (pAKT). On the other hand, phospho-S6 protein (pS6P, a down-stream target of mTOR) was strongly down-regulated by 6-PN and 8-PN after 4, 12 and $24 \mathrm{~h}$ (Fig. 5A). Thus, there was an obvious discrepancy between the expression of pAKT and pS6P. We therefore also determined the expression of P70S6 kinase and its phosphorylated form. 6-PN and 8-PN down-regulated P70S6 kinase protein expression in a time-dependent manner (Fig. 5A). Interestingly, its phosphorylated form (pP70S6 kinase) was not detectable, even in the control group (not shown). Therefore, we next investigated if S6P could be phosphorylated by a different mechanism. In this respect, activated ERK is able to phosphorylate the p90 ribosomal S6 kinase (pP90). pP90 also phosphorylates the S6P (in addition to the P70S6 kinase) [28, 29]. Since the pP70S6 kinase was absent in our cells, we hypothesized that the phosphorylation of the S6P was facilitated by the pERK/pP90 pathway, independent from P70S6 signaling. This hypothesis was 


\section{Cellular Physiology Cell Physiol Biochem 2018;51:543-556 \\ \begin{tabular}{ll|l} 
and Biochemistry & $\begin{array}{l}\text { DOl: 10.1159/000495275 } \\
\text { Published online: 20 November } 2018\end{array}$ & $\begin{array}{l}\text { ( } 2018 \text { The Author(s). Published by S. Karger AG, Basel } \\
\text { wwwer.com/cpb }\end{array}$ \\
\cline { 2 - 3 }
\end{tabular} \\ Venturelli et al.: 6-PN and 8-PN are Novel HDACi}

supported by the parallel down-regulation of the bands for pP90 (Thr359/Ser363) and pS6P $12 \mathrm{~h}$ after treatment with 6-PN, and the re-appearance of both bands after $24 \mathrm{~h}$ (Fig. $5 \mathrm{~A}$ ). In the 8-PN treatment group we detected a strong down-regulation of pERK after 12 and $24 \mathrm{~h}$ and an additional decrease of pP90 protein, which was accompanied by the parallel downregulation of pS6P. Together, these results suggest that the phosphorylation of the S6P was hampered via the down-regulation of the $\mathrm{pERK} / \mathrm{pP} 90$ pathway by the PN, independent from PI3K/AKT/P70S6 signaling (Fig. 5B). The Western blot and FACS experiments demonstrate that 6-PN and 8-PN-induced cytotoxicity on melanoma cells is not conducted by apoptosis induction, but rather by necrosis.

\section{Discussion}

Epigenetic alterations, in particular gene-specific DNA hypermethylation and histone acetylation, and thus dysregulated gene expression are hallmarks of cancer [30]. Because perturbations of the histone acetylation status contribute to the development and growth of different tumor types, they represent a promising target for cancer therapy. Certain dietary factors are known to modulate the chromatin structure, both by affecting DNA methylation and histone deacetylation and are therefore currently investigated in the context of cancer therapy and prevention [31]. Among these dietary compounds flavonoids are investigated for their anticancer activity and considerable effects on various cellular signaling pathways $[7,8]$. The prospective Multiethnic Cohort (MEC) study on 46027 non-hysterectomized postmenopausal women observed that a greater consumption of foods containing isoflavones, a flavonoid subgroup, is associated with a reduced risk of endometrial cancer [32].

In the present study, we modelled the interactions of 6-PN and 8-PN with HDAC enzymes in silico and and investigated their potential inhibition using in vitro models. Our in silico findings showed that both 6-PN and 8-PN fit in the catalytic pocket of human HDAC2, HDAC4, HDAC7 and HDAC8 and interact with the zinc ion of the active site indicating that 6-PN and 8-PN may be potential inhibitors of HDAC activity. To confirm this a number of different HDAC inhibition screening assays were used. All in vitro experiments identified 6-PN and 8-PN as distinct HDACi. As further proof for the observed HDACi activity, treatment of the human SK-MEL-28 melanoma cell line with 6-PN and 8-PN induced hyperacetylation of histone protein H3. Thus, 6-PN and 8-PN both feature a pronounced pan-HDACi activity. While most epignetically active dietary compounds have moderate activity, our results indicate a strong HDACi activity for 6-PN and 8-PN [33].

Epigenetic therapies are promising treatment options against hematological malignancies and solid tumors [21,30]. Epigenetic drugs are of particular interest for the therapy of tumors that are resistant against cytostatic agents such as melanoma. We therefore used the metastatic melanoma cell lines SK-MEL-28 (bearing a BRAFV600E mutation) and BLM (bearing an NRAS mutation) to evaluate the antiproliferative potency of 6-PN and 8-PN. Real-time cell monitoring and proliferation assays showed antiproliferative effects after single treatment with 6-PN and 8-PN. Especially concentrations between 50 and $100 \mu \mathrm{mol} / \mathrm{L}$ of both PN inhibited growth and viability of all the melanoma cells. As control HDACi, SAHA and VPA were used. Growth inhibition within $24 \mathrm{~h}$ was more pronounced after treatment with 6-PN than after treatment with the two control HDACi at similar or even higher concentrations. Our results are in line with previous reports that showed induction of cytotoxicity at similar concentrations for the breast, renal and prostate cancer cell lines after single treatment $[10,13,16,17,19]$.

Concentrations $<100 \mu \mathrm{mol} / \mathrm{L} 6$-PN or 8-PN rapidly induced a decline of the CI within the first $4 \mathrm{~h}$ of treatment. At this time point an increase of acetylation of histone complex $\mathrm{H} 3$ was detected indicating that the antiproliferative effect caused by the two different PN could partly be due to the newly found HDACi activity. However, we were unable to generate a direct link between the HDACi-activity and the decline of the CI. 
To further scrutinize the type of antiproliferative effects induced by the newly found HDACi, we performed Western blot analyses for caspase-3 (pro-apoptotic) and an extensive apoptosis screening (analyzing 35 proteins involved in apoptosis); however, apoptosis was not detected, which is in line with previous data [18]. The lack of apoptosis induction was verified by FACS analyses demonstrating that the PN did not increase the number of annexin $\mathrm{V}$ positive (apoptotic) cells, but instead induced a G2 cell cycle arrest in melanoma cells and increased the percentage of PI-positive (necrotic) cells. Necroptosis (the programmed form of necrosis, or inflammatory cell death), which is driven by $\mathrm{TNF} \alpha$, has recently been shown to be altered in neuronal cells by HDAC inhibitors such as SAHA (protects from necroptosis [34]) and VPA (induces necroptosis [35]). In malignantly transformed acute myeloid leukemia cells the HDACi MS275 enhanced necroptosis [36]). Because of the conflicting nature of the data (both inhibition and induction of necroptosis by HDACi in non-transformed cells) we did not experimentally address this aspect in the current work and can therefore only speculate on a possible modification of necroptosis by 6-PN and/or 8-PN. Next, we screened for an influence of 6-PN and 8-PN on melanoma-specific oncogenic pathways. Western blot analyses of SK-MEL-28 cells after PN-treatment yielded an inconsistent decrease of AKT and pAKT protein expression after treatment with 6-PN or 8-PN. This was accompanied by an irregular expression pattern of pS6P (down-stream target of mTOR) in SK-MEL-28 cells by 6-PN and 8-PN. However, we were able to find a plausible explanation for the ambiguous pAKT and pS6P blots after treatment with 6-PN or 8-PN: additional Western blot experiments suggested that the phosphorylation of the S6P was hampered via the alternative pERK/pP90 pathway [28], independent from P70S6 signaling.

Every novel epigenetic drug independent of its origin (e.g. nutrient or dietary component) requires a toxicity analysis to exclude unwanted side effects. In this respect, we recently tested the oral application of $500 \mathrm{mg}$ of 6-PN and 8-PN isolated from hops in vivo in healthy volunteers in a clinical trial. We did not detect any toxicity due to 6-PN and 8-PN in the healthy subjects of the clinical trial [37]. To determine the bioavailability of the compounds, we first validated a rapid and sensitive reversed-phase liquid chromatographic method for the quantification of 6-PN and 8-PN in plasma and urine [38]. The oral bioavailability of 8-PN was significantly higher than that of 6-PN [37].

\section{Conclusion}

In conclusion, we report in silico and in vitro evidence for distinct HDACi activities of the prenylflavonoids 6-PN and 8-PN for the first time. We demonstrated that 6-PN and 8-PN induced hyperacetylation of histone protein $\mathrm{H} 3$ in melanoma cells and reduced cell proliferation by an apoptosis-independent mechanism through induction of necrosis and G2-arrest. Further, we could show that both PN down-regulate pS6P via the pERK/pP90 pathway in SK-MEL-28 cells. Overall, our data suggest cell death may be induced by 6-PN and 8-PN via the interplay of inhibition of HDAC-activity and pS6P down-regulation, eventually leading to caspase-independent, necrotic-like cell death. Our current results and the results of our recent clinical trial [37] strongly suggest that 6-PN and 8-PN are interesting drug candidates for further clinical evaluation as epigenetically active anticancer agents and might in addition serve as model structures, suitable for novel epigenetic approaches for melanoma prevention and therapy.

\section{Acknowledgements}

This project was supported by the fortuene program of the University Hospital Tuebingen (1966-0-0), research grants of the European Foundation for Alcohol Research (ERAB, grant ref. EA 15 28), the Else-Uebelmesser-Stiftung of the University of Tuebingen, the Institutional Strategy of the Eberhard Karls University of Tuebingen (Deutsche Forschungsgemeinschaft 


\section{Cellular Physiology Cell Physiol Biochem 2018;51:543-556 and Biochemistry Published onlne: 201November $2018 \begin{aligned} & \text { (c) } 2018 \text { The Author(s). Published by S. Karger AG, Basel } \\ & \text { www.karger.com/cpb }\end{aligned}$}

Venturelli et al.: 6-PN and 8-PN are Novel HDACi

[DFG], ZUK 639) and the Wissenschaftsfoerderung der Deutschen Brauwirtschaft e.V. (B103). We further thank the Open Access Publishing Fund of the Eberhard Karls University of Tuebingen for the support. The authors also thank Andrea Schenk and Irina Smirnow for excellent assistance and Michael Bitzer, MD, for support and helpful discussion.

\section{Disclosure Statement}

The University of Tuebingen, Faculty of Medicine has a granted US patent (No. 9, 855, 242) entitled "Composition for an immunomodulation" involving 6-PN and 8-PN.

\section{References}

1 Albini A, Sporn MB: The tumour microenvironment as a target for chemoprevention. Nat Rev Cancer 2007;7:139-147.

-2 Lambert JD, Hong J, Yang GY, Liao J, Yang CS: Inhibition of carcinogenesis by polyphenols: evidence from laboratory investigations. Am J Clin Nutr 2005;81:284-291.

3 Leischner C, Burkard M, Pfeiffer MM, Lauer UM, Busch C, Venturelli S: Nutritional immunology: function of natural killer cells and their modulation by resveratrol for cancer prevention and treatment. Nutr J 2016;15:47.

4 Burkard M, Leischner C, Lauer UM, Busch C, Venturelli S, Frank J: Dietary flavonoids and modulation of natural killer cells: implications in malignant and viral diseases. J Nutr Biochem 2017;46:1-12.

5 Venturelli S, Burkard M, Biendl M, Lauer UM, Frank J, Busch C: Prenylated chalcones and flavonoids for the prevention and treatment of cancer. Nutrition 2016;32:1171-1178.

6 Haslam E: Practical Polyphenolics. From Structure to Molecular Recognition and Physiological Action. Cambridge, Cambridge University Press, 1998.

7 Hodek P, Trefil P, Stiborova M: Flavonoids-potent and versatile biologically active compounds interacting with cytochromes P450 Chem Biol Interact 2002;139:1-21.

$>8$ Pietta PG: Flavonoids as antioxidants. J Nat Prod 2000;63:1035-1042.

-9 Milligan SR, Kalita JC, Heyerick A, Rong H, De CL, De KD: Identification of a potent phytoestrogen in hops (Humulus lupulus L.) and beer. J Clin Endocrinol Metab 1999;84:2249-2252.

10 Busch C, Noor S, Leischner C, Burkard M, Lauer UM, Venturelli S: Anti-proliferative activity of hop-derived prenylflavonoids against human cancer cell lines. Wiener Med Wochenschr 2015;165:258-261.

11 Pepper MS, Hazel SJ, Humpel M, Schleuning WD: 8-prenylnaringenin, a novel phytoestrogen, inhibits angiogenesis in vitro and in vivo. J Cell Physiol 2004;199:98-107.

12 Rong H, Boterberg T, Maubach J, Stove C, Depypere H, Van Slambrouck S, Serreyn R, De Keukeleire D, Mareel M, Bracke M: 8-Prenylnaringenin, the phytoestrogen in hops and beer, upregulates the function of the E-cadherin/catenin complex in human mammary carcinoma cells. Eur J Cell Biol 2001;80:580-585.

13 Brunelli E, Minassi A, Appendino G, Moro L: 8-Prenylnaringenin, inhibits estrogen receptor-alpha mediated cell growth and induces apoptosis in MCF-7 breast cancer cells. J Steroid Biochem Mol Biol 2007;107:140148.

14 Diller RA, Riepl HM, Rose 0, Frias C, Henze G, Prokop A: Ability of prenylflavanones present in hops to induce apoptosis in a human Burkitt lymphoma cell line. Planta Med 2007;73:755-761.

15 Wesołowska O, Wiśniewski J, Sroda K, Krawczenko A, Bielawska-Pohl A, Paprocka M, Duś D, Michalak K: 8-Prenylnaringenin is an inhibitor of multidrug resistance-associated transporters, P-glycoprotein and MRP1Eur J Pharmacol 2010:644;32-40.

16 Brunelli E, Pinton G, Bellini P, Minassi A, Appendino G, Moro L: Flavonoid-induced autophagy in hormone sensitive breast cancer cells. Fitoterapia 2009;80:327-332.

17 Delmulle L, Bellahcène A, Dhooge W, Comhaire F, Roelens F, Huvaere K, Heyerick A, Castronovo V, De Keukeleire D: Anti-proliferative properties of prenylated flavonoids from hops (Humulus lupulus L.) in human prostate cancer cell lines. Phytomedicine 2006;13:732-734. 


\section{Cellular Physiology Cell Physiol Biochem 2018;51:543-556

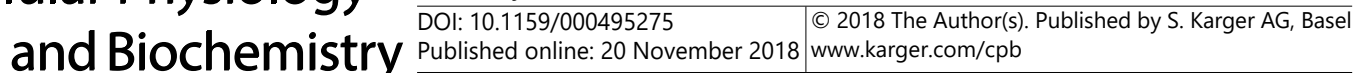 \\ Venturelli et al.: 6-PN and 8-PN are Novel HDACi}

18 Delmulle L, Vanden Berghe T, Keukeleire DD, Vandenabeele P: Treatment of PC-3 and DU145 prostate cancer cells by prenylflavonoids from hop (Humulus lupulus L.) induces a caspase-independent form of cell death. Phytother Res 2008;22;197-203.

19 Brunelli E, Pinton G, Chianale F, Graziani A, Appendino G, Moro L: 8-Prenylnaringenin inhibits epidermal growth factor-induced MCF-7 breast cancer cell proliferation by targeting phosphatidylinositol-3-OH kinase activity. J Steroid Biochem Mol Biol 2009;113:163-170.

-20 Busch C, Burkard M, Leischner C, Lauer UM, Frank J, Venturelli S: Epigenetic activities of flavonoids in the prevention and treatment of cancer. Clin Epigenet 2015;7:64.

-21 Johnstone RW: Histone-deacetylase inhibitors: novel drugs for the treatment of cancer. Nat Rev Drug Discov 2002;1:287-299.

22 Mai A: The therapeutic uses of chromatin-modifying agents. Expert Opin Ther Targets 2007;11:835-851.

-23 Zouboulis CC, Garbe C, Krasagakis K, Kruger S, Orfanos CE: A fluorometric rapid microassay to identify anti-proliferative compounds for human melanoma cells in vitro. Melanoma Res 1991;1:91-95.

24 Xing JZ, Zhu L, Jackson JA, Gabos S, Sun XJ, Wang XB, Xu X: Dynamic monitoring of cytotoxicity on microelectronic sensors. Chem Res Toxicol 2005;18:154-161.

25 Weiland T, Berger A, Essmann F, Lauer UM, Bitzer M, Venturelli S: Kinetic Tracking of Therapy-Induced Senescence Using the Real-Time Cell Analyzer Single Plate System. Assay Drug Dev Technol 2012;10:289295.

-26 Sinnberg T, Menzel M, Kaesler S, Biedermann T, Sauer B, Nahnsen S, Schwarz M, Garbe C, Schittek B: Suppression of casein kinase 1 alpha in melanoma cells induces a switch in beta-catenin signaling to promote metastasis. Cancer Res 2010;70:6999-7009.

-27 Berger A, Venturelli S, Kallnischkies M, Böcker A, Busch C, Weiland T, Noor S, Leischner C, Weiss TS, Lauer UM, Bischoff SC, Bitzer M: Kaempferol, a new nutrition-derived pan-inhibitor of human histone deacetylases. J Nutr Biochem 2013;24:977-985.

-28 Ray-David H, Romeo Y, Lavoie G, Déléris P, Tcherkezian J, Galan JA, Roux PP: RSK promotes G2 DNA damage checkpoint silencing and participates in melanoma chemoresistance. Oncogene 2013;32:4480-4489.

29 Mendoza MC, Er EE, Blenis J: The Ras-ERK and PI3K-mTOR pathways: cross-talk and compensation. Trends Biochem Sci 2011;36:320-328

-30 Ellis L, Atadja PW, Johnstone RW: Epigenetics in cancer: targeting chromatin modifications. Mol Cancer Ther 2009;8:1409-1420.

-31 Meeran SM, Ahmed A, Tollefsbol TO: Epigenetic targets of bioactive dietary components for cancer prevention and therapy. Clin Epigenetics 2010;1:101-116.

-32 Ollberding NJ, Lim U, Wilkens LR, Setiawan VW, Shvetsov YB, Henderson BE, Kolonel LN, Goodman MT: Legume, soy, tofu, and isoflavone intake and endometrial cancer risk in postmenopausal women in the multiethnic cohort study. J Natl Cancer Inst 2012;104:67-76.

-33 Dashwood RH, Myzak MC, Ho E: Dietary HDAC inhibitors: time to rethink weak ligands in cancer chemoprevention? Carcinogenesis 2006;27:344-349.

-34 Wang D, Zhao M, Chen G, Cheng X, Han X, Lin S, Zhang X, Yu X: The histone deacetylase inhibitor vorinostat prevents TNF $\alpha$-induced necroptosis by regulating multiple signaling pathways. Apoptosis 2013;18:13481362.

-35 Bollino D, Balan I, Aurelian L: Valproic acid induces neuronal cell death through a novel calpain-dependent necroptosis pathway. J Neurochem 2015;133:174-186.

-36 Steinwascher S, Nugues AL, Schoeneberger H, Fulda S: Identification of a novel synergistic induction of cell death by Smac mimetic and HDAC inhibitors in acute myeloid leukemia cells. Cancer Lett 2015;366:32-43.

37 Calvo-Castro LA, Burkard M, Sus N, Scheubeck G, Leischner C, Lauer UM, Bosy-Westphal A, Hund V, Busch C, Venturelli S, Frank J: The oral bioavailability of 8-Prenylnaringenin from hops (Humulus lupulus L.) in healthy women and men is significantly higher than that of its positional isomer 6-Prenylnaringenin in a randomized crossover trial. Mol Nutr Food Res 2018;62:e1700838.

-38 Sus N, Schlienz J, Calvo-Castro LA, Burkard M, Venturelli S, Busch C, Frank J: Validation of a rapid and sensitive reversed-phase liquid chromatographic method for the quantification of prenylated chalcones and flavanones in plasma and urine. NFS Journal 2018;10:1-9. 